\title{
Serum Pepsinogen and Gastric Cancer Screening
}

\author{
Chizu Mukoubayashi, Kimihiko Yanaoka, Hiroshi Ohata, Kenji Arii, Hideyuki Tamai, \\ Masashi Oka and Masao Ichinose
}

\begin{abstract}
Since the 1990's, the test for serum pepsinogen as a marker for chronic atrophic gastritis has been incorporated into gastric cancer screening programs, on a trial basis, to identify people at high risk for gastric cancer. The addition of the serum test to the cancer screening program has been shown to improve the detection rate of cancer and pepsinogen testing is useful in detecting early-stage gastric cancers arising from atrophic gastric mucosa, which macroscopically tend to be elevated and histologically differentiated. Furthermore, the cost for the detection of a single cancer case is much less than that for conventional screening. Thus, with the introduction of pepsinogen testing, complimenting barium X-ray, a more efficient screening system is available.
\end{abstract}

Key words: gastric cancer, screening, pepsinogen, atrophic gastritis, gastric cancer screening, high-risk group

(DOI: 10.2169/internalmedicine.46.6181)

\section{Introduction}

Since the mid-1960s, the Japanese government has advocated gastric cancer screening programs based mainly on double-contrast barium X-ray (1). As a result, a significant reduction in mortality and morbidity from gastric cancer has been attained (2-6). However, the number of people who undergo gastric cancer screening has not increased in recent years. Since the 1990's, the test for serum pepsinogen (PG) as a marker for chronic atrophic gastritis has been incorporated into gastric cancer screening programs, on a trial basis, to identify people who would benefit most from gastric cancer screening (7-12). Ever since PG assay kits became commercially available, numerous centers in Japan have measured serum PG levels as a part of gastric cancer screening. The results have shown that PG testing is useful in detecting early-stage gastric cancer (7-12). After 15 years of experience, the effectiveness of PG testing is receiving wide recognition. The present article summarizes the clinical importance of PG testing and introduces our recent investigations on gastric cancer screening programs incorporating PG testing.

Pepsinogen Testing
Pepsinogen is a precursor for pepsin, a digestive enzyme
specifically produced in the gastric mucosa. The human
stomach expresses two isozymogens, PGI and PGII, with
different biochemical and immunological properties (13).
Histological studies based on immunohistochemistry using
specific antibodies or in-situ hybridization have clearly iden-
tified cells that produce PGI and PGII (14-16). While PGI is
produced in chief and mucous neck cells, PGII is produced
not only in these cells, but also in the cardiac, pyloric, and
duodenal Brunner gland cells. The distribution of PGII-
producing cells is thus widespread from the entire stomach
to the duodenum. Figure 1 shows the distribution of cells
producing PGI and PGII in relation with those producing
gastric acid and gastrin. Histologically, the localization of
PGI-producing cells is limited to an acid-secreting gland, the
fundic gland, and that of PGII-producing cells is observed
in the fundic and pyloric glands (gastrin-secreting area), and
also in the duodenal gland. Figure 1 shows the two-layer
structure of PG-producing cell distribution. Pepsinogen is
mainly excreted into the stomach lumen, but about $1 \%$ of
the total enters into the blood stream, although the mecha-
nism is unknown. Studies have clarified that serum PG lev-
els reflect the morphology and function of the gastric mu-

Pepsinogen is a precursor for pepsin, a digestive enzyme specifically produced in the gastric mucosa. The human stomach expresses two isozymogens, PGI and PGII, with different biochemical and immunological properties (13). Histological studies based on immunohistochemistry using specific antibodies or in-situ hybridization have clearly identified cells that produce PGI and PGII (14-16). While PGI is produced in chief and mucous neck cells, PGII is produced not only in these cells, but also in the cardiac, pyloric, and duodenal Brunner gland cells. The distribution of PGIIproducing cells is thus widespread from the entire stomach to the duodenum. Figure 1 shows the distribution of cells producing PGI and PGII in relation with those producing gastric acid and gastrin. Histologically, the localization of PGI-producing cells is limited to an acid-secreting gland, the fundic gland, and that of PGII-producing cells is observed in the fundic and pyloric glands (gastrin-secreting area), and structure of PG-producing cell distribution. Pepsinogen is mainly excreted into the stomach lumen, but about $1 \%$ of the total enters into the blood stream, although the mechaels reflect the morphology and function of the gastric mu-

Second Department of Internal Medicine, Wakayama Medical University, Wakayama

Received for publication August 13, 2006; Accepted for publication September 21, 2006

Correspondence to Dr. Masao Ichinose, ichinose@ wakayama-med.ac.jp 


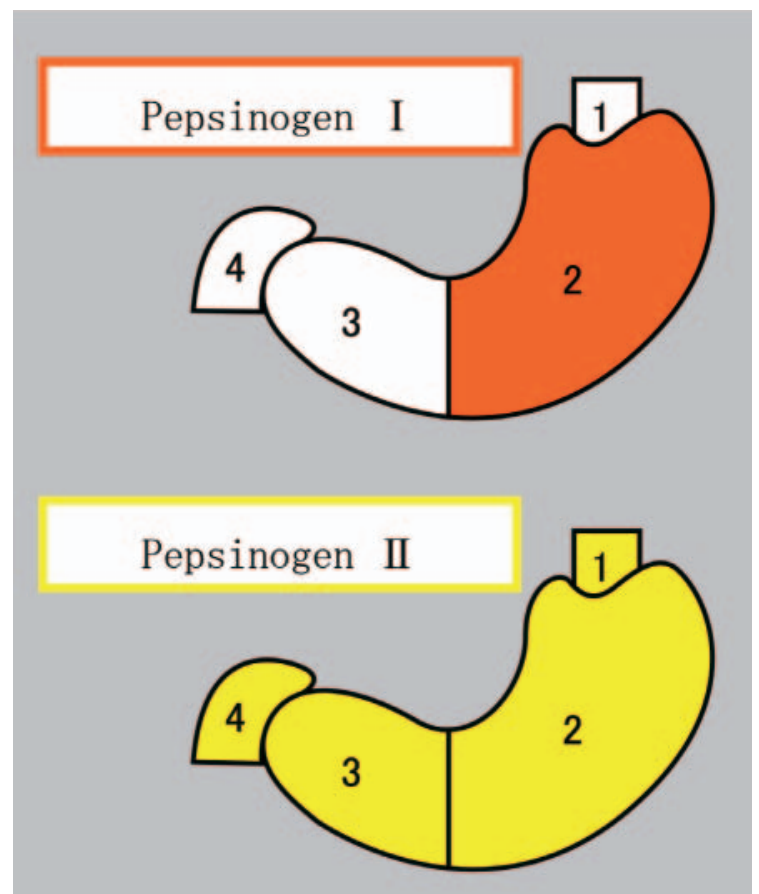

Figure 1. Relationship between the distribution of pepsinogen in gastric mucosa and the secretion of gastric acid and gastrin. 1: Cardiac gland region. 2: Fundic gland region (gastric acid). 3: Pyloric gland region (gastrin). 4: Duodenal Brunner gland region.

cosa and also various pathological conditions such as inflammation (17-23). It is important to note that, during the process of chronic atrophic gastritis, mucosal atrophy advances from the side of the pyloric gland towards the oral side, and that PGI levels and PGI/PGII ratios decrease with advancement in mucosal atrophy (18-20, 23) (Fig. 2). These clinically extremely important changes in serum PG levels are due to the above-mentioned unique distribution of PGproducing cells in gastric mucosal epithelia. In addition, the results of past pathological and epidemiological studies have shown that a strong correlation exists between chronic atrophic gastritis and differentiated gastric cancer development, and thus, chronic atrophic gastritis is considered to be a precancerous lesion (24-27). Pepsinogen testing is based on the correlation between chronic atrophic gastritis and gastric cancer development on the one hand, and the correlation between chronic atrophic gastritis and low PG level on the other. By the introduction of PG testing, which allows the identification of subjects at high risk for gastric cancer, and also by the introduction of endoscopy for the screening of the PG test-positive subjects, the efficiency of gastric cancer detection can be improved dramatically.

From the perspective of complementing conventional radiography, the following four methods for gastric cancer screening utilizing PG testing have been proposed (Fig. 3). In the Concurrent Method, both PG testing and X-ray imaging are performed at the same time, and while this method is ideal for early detection because the two tests have different mechanisms of detection, it is expensive and the number

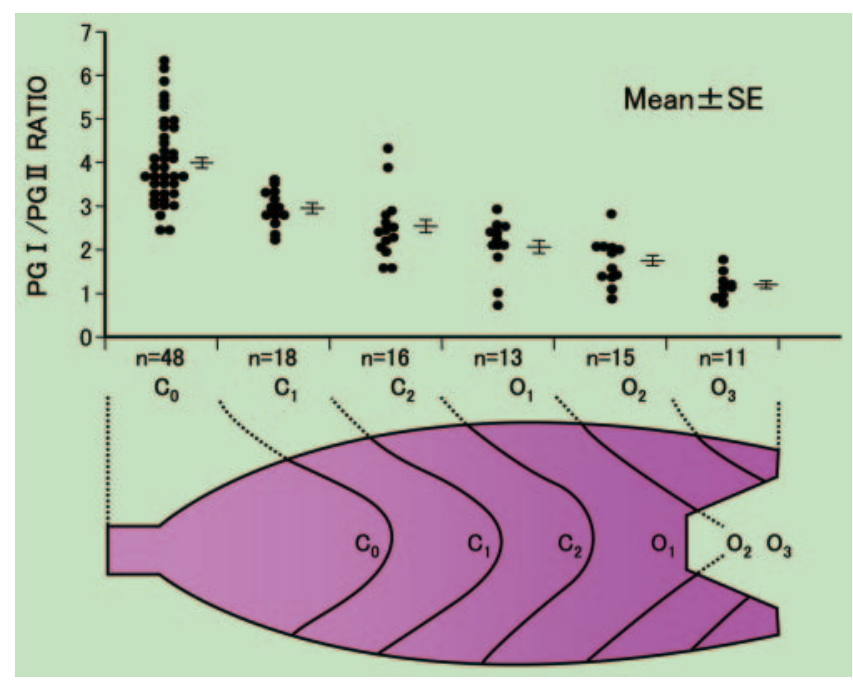

Figure 2. Serum pepsinogen I/II ratio and gland boundary as assessed by endoscopic Congo red staining

of subjects requiring further examination by endoscopy is larger than in the other three methods. In the Two-stage Method, PG testing is performed to detect early-stage cancer and X-ray imaging is performed to pick up PG-negative cancer, that is, cancer that will develop from the stomach with mild atrophic gastritis. With this method, the results of PG testing should ideally be available quickly so that X-ray imaging can be performed on the same day if necessary. Third, as the Alternative Method, PG testing and X-ray imaging are performed on alternative years. This method is not useful for dynamic populations, such as regional screenings in big cities, but is useful for static populations, such as in the workplace in our country. Finally, the last one is the Single PG Method. This method does not include barium Xray screening, and the cancer screening can be combined with a general health check-up that can be carried out by analyzing blood samples. However, as described above, there does exist PG-negative gastric cancer accounting for about $30-40 \%$ of total gastric cancer, and these cancers easily escape diagnosis by the serum tests. Nonetheless, this method is useful for encouraging people to undergo gastric cancer screenings in areas where the number of people receiving the conventional cancer screening remains relatively constant. This method may also be useful as part of the screening programs that are carried out for patients 30 years old and every 5-10 years thereafter, such as the screening carried out by the municipal government in our country.

\section{Actual State of Gastric Cancer Screening Util- izing Serum PG Testing}

Of the above four methods, we have developed a gastric cancer screening program that concurrently performs PG testing and barium digital radiography (DR), and have conducted research to establish an efficient gastric cancer screening program (28). In other words, over a period of 7 years from 1995 to 2002 , a total of 17,647 men with a 


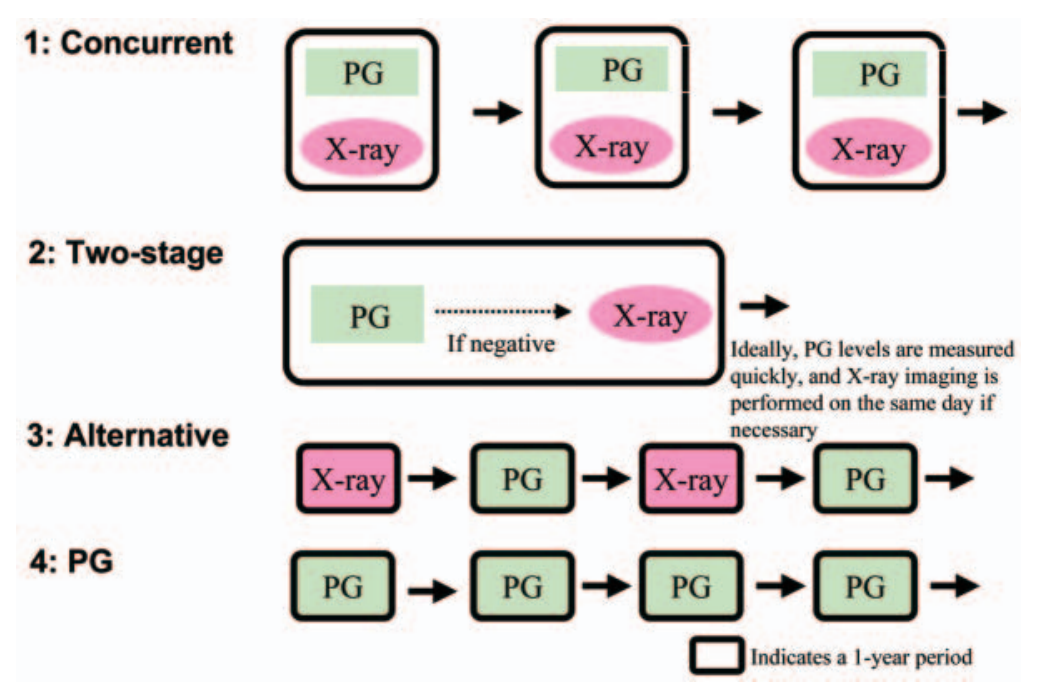

Figure 3. Pepsinogen test procedures.

mean age of 50.4 \pm 5.4 years (range, 40-60 years) received gastric cancer screenings at their workplaces. In the primary screening, serum PG testing and barium X-ray with DR were combined, and if either or both of the two screening methods were positive, the subject was further screened by upper gastrointestinal endoscopy. Serum PG levels were measured by radioimmunoassay (RIA) (29). After taking into account the manpower necessary for gastroscopy, the cutoff values for the PG test were set at PGI $\leq 50 \mu \mathrm{g} / \mathrm{l}$ and $\mathrm{PGI} / \mathrm{II}$ ratio $\leq 3.0$; these criteria give a positive rate of approximately $20 \%$ in all subjects. The detection rate of gastric cancer during the observation period was $0.28 \%$, markedly higher than that by conventional barium X-ray with photofluorography $(0.1 \%)(30)$, clarifying that this concurrent method more efficiently detects gastric cancer than the conventional screening method. Of the gastric cancers detected, $63.3 \%$ were PG-positive and $69.4 \%$ were DRpositive, but only $32.7 \%$ were both PG- and DR-positive. Of the gastric cancers detected, $88 \%$ were early-stage gastric cancer. Early-stage cancer accounted for $100 \%$ of cancers detected by PG, $83 \%$ of cancers detected by DR, and $81 \%$ of cancers detected by both PG and DR. In addition, the size of cancer detected by PG was significantly smaller than that detected by DR, and $89 \%$ of these cancers were intramucosal tumors. Conversely, intramucosal cancers only accounted for about half of the cancers detected by DR. Pepsinogen testing is thus useful in detecting small cancers arising from atrophic gastric mucosa, which macroscopically tend to be elevated and histologically differentiated. As a result, the method is superior for detecting early-stage cancer. All tumors were completely removed by surgery or endoscopic mucosal resection (EMR). The latter procedure is particularly suited for small, differentiated mucosal cancer (especially elevated types) (31). In fact, $44 \%$ of cancers detected by PG were treated by EMR, and this figure was higher when compared to the other groups (DR, 22\%; Combined, 12\%). In this manner, PG testing greatly improves the quality of life of patients, because gastric cancer can be detected in the early stages. In addition, the cost for the detection of a single cancer case was much less than that for conventional screening ( $¥ 4,408,543[\$ 37,360]$ by conventional screening vs. $¥ 2,275,387$ [ $\$ 19,282]$ by PG testing). Figure 4 shows an example of early-stage gastric cancer as detected by PG or DR. In a PG-negative DR-positive patient (case A), a 10-mm type IIc + III lesion was located in the lesser curvature of the gastric angle. Partial gastrectomy was then performed and histopathological examination of the excised tissue specimen showed diffuse-type mucosal cancer. In a PG-positive DR-negative patient (case B), endoscopy revealed an 8-mm IIa lesion in the lesser curvature of the proximal antrum, and histological analysis of a biopsy specimen showed intestinal-type mucosal cancer. The cancer was subsequently removed by EMR. Both patients were asymptomatic, and it is noteworthy to add that if only PG or DR had been performed, these lesions could have been missed. Because PG and DR detect gastric cancer based on different clinicopathological mechanisms, a combination of the two methods can improve the efficacy of screening and may lower the mortality rate for gastric cancer in the long run. To further refine this screening program, studies should be done to ascertain how and on which groups of subjects the two tests should be performed.

\section{Gastric Cancer Screening Based on Individual Cancer Risk}

Over a period of about 8 years, we followed about 5,000 middle-aged men to ascertain the significance of atrophic gastritis as a risk factor for gastric cancer in relation to Helicobacter pylori (HP) infection (32). H. pylori infection was assessed based on serum anti-HP IgG antibody, while advancements in chronic atrophic gastritis were assessed based on the PG test; test-positive criteria were PGI $\leq 70 \mu \mathrm{g} / \mathrm{l}$ and PGI/II ratio $\leq 3.0$. Furthermore, based on the results of both tests, the subjects were divided into four groups according to the severity of chronic atrophic gastritis: Group A, $\mathrm{HP}(-)$ 


\section{Case A}
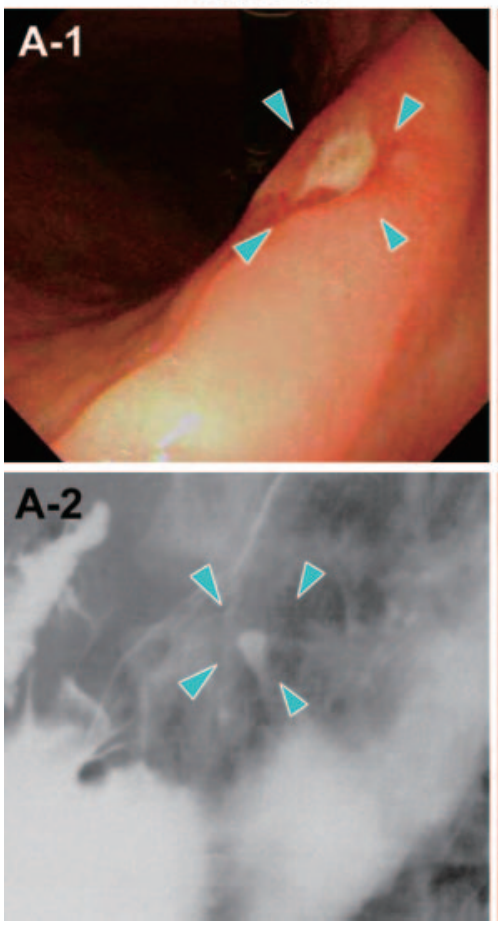

\section{Case B}

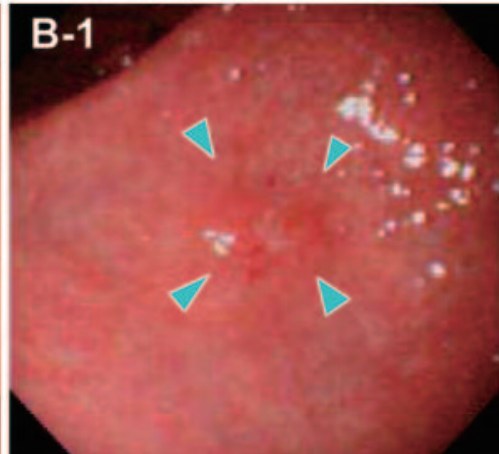

\section{B-2}

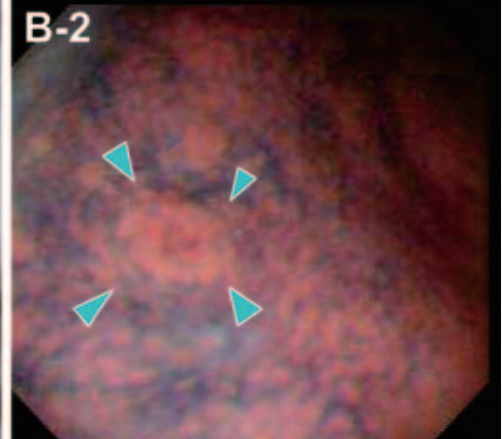

Figure 4. Representative stomach cancers detected by gastric cancer screening. Case A: DR-positive and PG-negative 10-mm type IIc + III lesion located in the lesser curvature of the gastric angle. Serum PGI was $44.6 \mu \mathrm{g} / \mathrm{l}$ and the PG I/II ratio was 3.3. Case B: DR-negative and PG-positive 8-mm type IIa lesion located in the lesser curvature of the proximal antrum as indicated by the arrowheads. Serum PGI was $39.5 \mu \mathrm{g} / \mathrm{l}$ and the PG I/II ratio was 1.

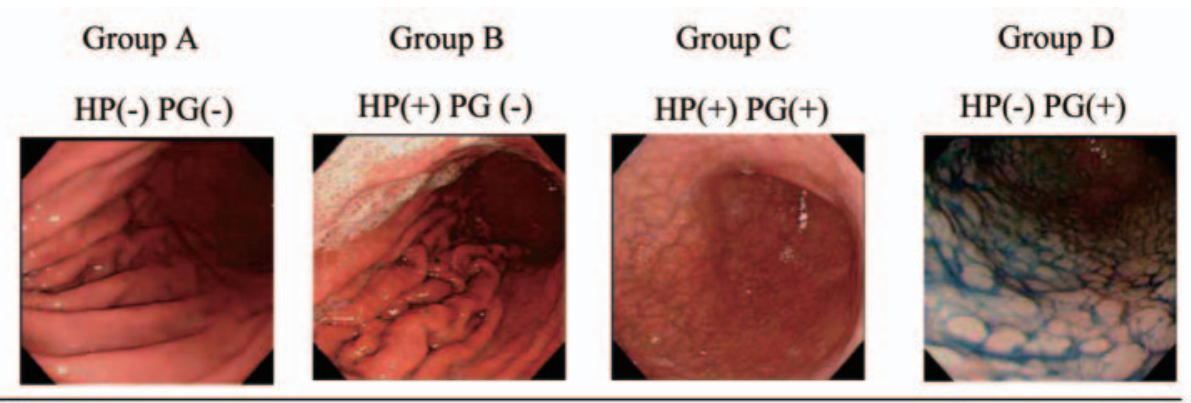

\begin{tabular}{ccccc}
$\begin{array}{c}\text { Annual } \\
\text { incidence of } \\
\text { stomach cancer }\end{array}$ & $0 \%$ & $\begin{array}{c}\text { Approximately } \\
0.1 \%\end{array}$ & $\begin{array}{c}\text { Approximately } \\
0.25 \%\end{array}$ & $\begin{array}{c}\text { Approximately } \\
1 \%\end{array}$ \\
\hline $\begin{array}{c}\text { Ratio to total } \\
\text { population }\end{array}$ & $20 \%$ & $50 \%$ & $30 \%$ & $0.7 \%$ \\
\hline Screening methed & $\begin{array}{c}\text { Possible to exclude } \\
\text { from stomach } \\
\text { cancer screening }\end{array}$ & X-ray imaging & Endoscopy \\
\hline
\end{tabular}

Figure 5. Improving the efficiency of gastric cancer screening. Hp: serum anti-H.pylori antibody; Pg: serum pepsinogen. * excluding eradicated cases. 
PG(-); Group B, HP(+) PG(-); Group C, HP(+) PG(+); and Group D, HP(-) PG(+). In other words, Group A included subjects who were without HP infection and with healthy stomach, Group B included subjects with HP infection but without atrophic gastritis, Group C included subjects who had atrophic gastritis induced by HP infection, and Group D included subjects with extensive atrophic gastritis together with widespread intestinal metaplasia, which led to a reduction in HP load in the stomach and finally to spontaneous eradication. Thus, group D comprised a group of subjects with metaplastic gastritis (Fig. 5). The annual incidence of gastric cancer in Group A was $0 \%$, in Group B $0.1 \%$, in Group C $0.25 \%$, and in Group D $1 \%$, and the hazards ratio of gastric cancer significantly increased with the progression of gastritis (32). The results also clarified that gastric cancer was extremely rare in Group A (subjects with healthy stomachs and without HP infection). While further investigations are needed, Group A may be excluded from gastric cancer screening. In other words, the efficacy of gastric cancer screening can be improved by testing only Groups B-D. Because double contrast barium X-ray is efficient at detecting lesions with a depressed or ulcerated morphology $(33,34)$, we believe that barium X-ray should be performed on Group B subjects, in which acid secretion is not reduced and cancerous lesions tend to be depressed or ulcerated (35, 36). In contrast, endoscopy should be performed on Groups $\mathrm{C}$ and D (high-risk groups), in which acid secretion is reduced and the cancers tend to have elevated morphology $(35,36)$.

These findings suggest that, in the future, gastric cancer screening should be performed after assessing individual cancer risk based on the combination of serum PG levels and HP antibody. Needless to say, highly sensitive radiography such as DR will improve the efficiency of gastric cancer screening.

\section{References}

1. Ichinose M, Yahagi N, Oka M, et al. Screening for gastric cancer in Japan. in:Cancer Screening-Practical Guide for Physicians. Wu GY, Aziz K, Eds. Humana Press, Totowa, 2001: 87-102.

2. Oshima A, Hanai A, Fujimoto I. Evaluation of a mass screening program for stomach cancer. Natl Cancer Inst Monograph 53: 181-186, 1979.

3. Hisamichi S, Sugahara N. Mass screening for gastric cancer by Xray examination. Jpn J Clin Oncol 11: 211-233, 1984.

4. Oshima A, Hirata N, Ubukata T, Umeda K, Fujimoto I. Evaluation of mass screening program for stomach cancer with a case-control study design. Int J Cancer 38: 829-833, 1986.

5. Fukao A, Tsubono Y, Tsuji I, Hisamichi S, Sugahara N, Takano A. The evaluation of screening for gastric cancer in Miyagi Prefecture, Japan: a population-based case-control study. Int $\mathrm{J}$ Cancer 60: 45-48, 1995.

6. Abe Y, Mitsushima T, Nagatani K, Ikuma H, Minamihara Y. Epidemiological evaluation of the protective effect for dying of stomach cancer by screening program for stomach cancer with applying a method of case-control study - a study of a efficient screening programme for a stomach cancer (in Japanese). Nippon Shokakibyo Gakkai Zasshi (Jpn J Gastroenterol) 92: 836-845, 1995.

7. Miki K, Ichinose M, Ishikawa K, Yahagi N, Matsushima M, Kakei N, Tsukada S, Kido M, Ishihama S, Shimizu Y, Suzuki T, Kurokawa K. The clinical application of the serum pepsinogen I and II levels as a mass screening method to detect stomach cancer. Jpn J Cancer Res 84: 1086-1090, 1993.

8. Kodoi A, Yoshihara M, Sumii K, Haruma K, Kajiyama G. Serum pepsinogen in screening for gastric cancer. J Gastroenterol 30: 452-460, 1995.

9. Hattori Y, Tashiro H, Kawamoto T, Kodama Y. Sensitivity and specificity of mass screening for gastric cancer using the measurement of serum pepsinogens. Jpn J Cancer Res 86: 1210-1215, 1995.

10. Kitahara F, Kobayashi K, Sato T, Kojima Y, Araki T, Fujino MA. Accuracy of screening for gastric cancer using serum pepsinogen concentrations. Gut 44: 693-697, 1999.

11. Yoshihara M, Sumi K, Haruma K, Kiyohira K, Hattori N, Tanaka $\mathrm{S}$, et al. The usefulness of gastric mass screening using serum pepsinogen levels compared with photofluorography. Hiroshima J Med Sci 46: 81-86, 1997.
12. Miki K, Morita M, Sasajima M, Hoshina R, Kanda E, Urita Y. Usefulness of gastric cancer screening using the serum pepsinogen test method. Am J Gastroenterol 98: 735-739, 2003.

13. Samloff IM. Pepsinogens, pepsins, and pepsin inhibitors. Gastroenterology 60: 586-604, 1971.

14. Samloff IM. Cellular localization of group I pepsinogens in human gastric mucosa by immunofluorescence. Gastroenterology $\mathbf{6 1}$ : 185-188, 1971.

15. Samloff IM, Liebman WM. Cellular localization of the group II pepsinogens in human stomach and duodenum by immunofluorescence. Gastroenterology 65: 36-42, 1973.

16. Sano J, Miki K, Ichinose M, Kimura M, Kurokawa K, Aida T, Ishizaki M, Asano G, Masugi Y, Wong RNS, Takahashi K. In situ localization of pepsinogen I and II mRNA in human gastric mucosa. Acta Pathol Jpn 39: 765-771, 1989.

17. Hirschowitz BI. Pepsinogen: its origin, secretion, and excretion. Physiol Rev 37: 475-511, 1957.

18. Samloff IM, Varis K, Ihamaki T, Siurala M, Rotter JI. Relationships among serum pepsinogen I, serum pepsinogen II, and gastric mucosa histology. A study in relatives of patients with pernicious anemia. Gastroenterology 83: 204-209, 1982.

19. Sipponen P, Samloff IM, Saukkonen M, Varis K. Serum pepsinogens I and II and gastric mucosal histology after partial gastrectomy. Gut 26: 1179-1182, 1985.

20. Nomura AMY, Stemmermann GN, Samloff IM. Serum pepsinogen I as a predictor of stomach cancer. Ann Int Med 93: 537-540, 1980.

21. Rotter JI, Sones JQ, Samloff IM, et al. Duodenal-ulcer disease associated with elevated serum pepsinogen I. An inherited autosomal dominant disorder. N Engl J Med 300: 63-66, 1979.

22. Samloff IM, Stemmermann GN, Heilbrun LK, Nomura A. Elevated serum pepsinogen I and II levels differ as risk factors for duodenal ulcer and gastric ulcer. Gastroenterology 90: 570-576, 1986.

23. Miki K, Ichinose M, Shimizu A, Huang SC, Oka H, Furihata C, Matsushima T, Takahashi K. Serum pepsinogens as a screening test of extensive chronic gastritis. Gastroenterol Jpn 22: 133-141, 1987.

24. Imai $\mathrm{T}$, Kubo $\mathrm{T}$, Watanabe H. Chronic gastritis in Japanese with reference to high incidence of gastric carcinoma. J Natl Cancer Inst 47: 179-195, 1971. 
25. Siurala M, Vuorinen Y. Follow-up studies of patients with superficial gastritis and patients with a normal gastric mucosa. Acta Med Scand 173: 45-52, 1963.

26. Munoz N, Matko I. Histological types of gastric cancer and its relationship with intestinal metaplasia. Recent Results Cancer Res 39: 99-105, 1972

27. Cheli R, Santi L, Ciancamerla G, Canciani G. A clinical and statistical follow-up study of atrophic gastritis. Am J Dig Dis 18: 1061-1065, 1973

28. Ohata H, Oka M, Yanaoka K, et al. Gastric cancer screening of a high-risk population in Japan using serum pepsinogen and barium digital radiography. Cancer Sci 96: 713-720, 2005.

29. Ichinose M, Miki K, Furihata C, Kageyama T, Hayashi R, Niwa H, Oka H, Matsushima T, Takahashi K. Radioimmunoassay of serum group I and group II pepsinogens in normal controls and patients with various disorders. Clin Chim Acta 126: 183-191, 1982.

30. Koga M, Miyakawa K, Ikeda S. Annual Report of Gastroenterological Mass Survey in Japan, 2002,The Japanese Society of Gastroenterological Mass Survey. Tokyo, 2004: 96-115.

31. Nishi $M$, Ishihara $S$, Nakajima $T$, Ohta $K$, Ohyama $S$, Ohta $H$.
Chronological changes of characteristics of early gastric cancer and therapy: experience in the Cancer Institute Hospital of Tokyo, 1950-1994. J Cancer Res Clin Oncol 121: 535-541, 1995.

32. Ohata H, Kitauchi S, Yoshimura N, et al. Progression of chronic atrophic gastritis associated with Helicobacter pylori infection increases risk of gastric cancer. Int J Cancer 109: 138-143, 2004.

33. Tsuchigame N, Urata J, Ueno S, et al. Detectability of gastric cancer in mass survey using indirect photofluorography. J Gastroent Mass Survey 33: 456-461, 1995 (in Japanese).

34. Shibuya D. Characteristics of X-ray-positive and pepsinogen testnegative gastric cancer and diagnostic imaging techniques for such cancer. Future gastric cancer screening: best approach based on barium X-ray and pepsinogen test. Medical View, Tokyo, 2002: 34-37 (in Japanese).

35. Tatsuta M, Okuda S, Taniguchi H, Tamura H. Gross and histological types of early gastric carcinomas in relation to the acidsecreting area. Cancer 43: 317-321, 1979.

36. Fujishiro M, Oka M, Yahagi N, et al. Correlation of serum pepsinogens and gross appearances combined with histology in early gastric cancer. J Exp Clin Cancer Res 25: 207-212, 2006.

(C) 2007 The Japanese Society of Internal Medicine http://www.naika.or.jp/imindex.html 